\title{
The Intestinal Evacuation and Maximum Daily Consumption of Purified Formulated Diets by Juvenile Grass Carp (Ctenopharyngodon idella)
}

\author{
Zhen-Yu Du ${ }^{1,2, *}$, Li-Xia Tian ${ }^{1}$, Gui-Ying Liang ${ }^{1}$, Han-Bing Lan $^{3}$ and Yong-Jian Liu ${ }^{1 *}$ \\ ${ }^{I}$ Institute of Aquatic Economic Animals, School of Life Sciences, Sun Yat-sen University, 510275 Guangzhou, P.R. \\ China \\ ${ }^{2}$ National Institute of Nutrition and Seafood Research (NIFES), 5005 Bergen, Norway \\ ${ }^{3}$ Guangdong Academy of Agriculture Sciences, 510640 Guangzhou, P.R. China
}

\begin{abstract}
The intestinal evacuation and maximum daily consumption of two formulated diets with different lipid content (6 and 10\%) was examined in juvenile grass carp at $28^{\circ} \mathrm{C}$. Fish were fed formulated diets to satiety and removed at 1 hour interval for intestine weighing. The study showed that both diets were evacuated from intestine in $12 \mathrm{~h}$ and the process of evacuation was expressed by linear regression. In the later study of maximum daily consumption, fish were fed formulated diets to satiety four times in a single day. The sum of diet consumption in the day was recorded. The experiment was repeated in $4,7,10,13,16,19,22$ day by the same fish. The result showed the maximum daily consumption of two formulated diets is $3.64 \pm 0.23 \%$ body weight $\left(416.79 \pm 28.84 \mathrm{~J} / \mathrm{g} . \mathrm{d}^{-1}\right)$ and $3.75 \pm 0.16 \%$ body weight $(481.73 \pm 19.44$ $\left.\mathrm{J} / \mathrm{g} \cdot \mathrm{d}^{-1}\right)$.
\end{abstract}

Key Words: Grass carp, intestinal evacuation, maximum daily consumption, formulated diet.

\section{INTRODUCTION}

The rate of gastrointestinal evacuation is one of the major determinants of feeding rate [1-3]. Many factors such as temperature, meal size, fish size, dietary composition and feeding frequency will influence gastrointestinal evacuation [4-8]. Gastrointestinal or gastric evacuation of some fish have been studied [1,4,5,7-14], but these species were carnivorous or omnivorous, also with well-developed stomach. The information on the intestinal evacuation in grass carp (Ctenopharyngodon idella), an herbivorous and stomachless finfish, are absent.

The daily food consumption of fish is important in drawing up a feeding schedule in nutrition research and aquaculture productivity, but it is inconstant and affected by water temperature, fish size, food species and photoperiod [15-19]. However, we hypothesized that in a relative constant aquatic environment, such as a good-managed recirculating system in lab, the maximum daily consumption of same fish should be constant.

The object of the present study was to measure the intestinal evacuation and maximum daily consumption of formulated diet in juvenile grass carp. At the same time, in order to know whether diets with different energy level could affect these indexes in grass carp as well as carnivorous species, two diets with different energy level were used.

*Address correspondence to these authors at the National Institute of Nutrition and Seafood Research (NIFES), Postboks 2029 Nordnes, 5817 Bergen, Norway; Tel: +47 91132279; Fax: +47 5590 5298; E-mail: zdu@nifes.no; Institute of Aquatic Economic Animals, Sun Yat-sen University, Xin'gang Xi, Road, 510275 Guangzhou, P.R. China; Tel: +86 84110789; E-mail: edls@mail.sysu.edu.cn

\section{MATERIALS AND METHODOLOGY}

\section{Fish and Diets}

The grass carp used in experiments was the strain which is long used in aquaculture and the fish was cultured in our own fish farm before moving in lab. The initial weight of juvenile grass carp was $3.4 \pm 0.12 \mathrm{~g}$ (mean $\pm \mathrm{SD}$ )g. The two experiments were carried out in a recirculating aquatic system consisted of 18 fiberglass tanks (100 L). The fish were acclimated to experimental condition and diet for 2 weeks. During the acclimating period, fish were fed with lipid-free experimental diet (GE $2312 \mathrm{kcal} \cdot \mathrm{kg}^{-1}$ ) at $1 \%$ body weight per day $(\mathrm{BW} / \mathrm{d})$. The rate of flow in the system was $5 \mathrm{~L} \cdot \mathrm{min}^{-1}$. During the two experiments, the water temperature, dissolved oxygen, $\mathrm{pH}$ and ammonia were $27.5-28.5^{\circ} \mathrm{C}$, 6.75$7.46 \mathrm{mg} \cdot \mathrm{L}^{-1}, 7.61-7.97$ and $0.08-0.26 \mathrm{mg} \cdot \mathrm{L}^{-1}$, respectively. The purified formulated diets were prepared as described by [20], and were stored at $-30^{\circ} \mathrm{C}$ until use. The ingredients of diets were shown in Table $\mathbf{1}$.

\section{Experimental Progress}

After 2 weeks of acclimation, fish were distributed randomly into 12 tanks (30 fish/tank, 6 tanks for each experiment). In order to study intestinal evacuation, $48 \mathrm{~h}$-fasted fish were fed the formulated diets to visual satiety at 9:00AM. Six fish (two fish per tank) were then gently removed at $1 \mathrm{~h}$ intervals for intestinal content weighing until the intestinal content was emptied entirely in all the samples. At the same time of removing fish, the remaining diet or faeces were cleaned up. The percentage of intestinal content weight (\% body weight) was used for statistical analysis. The experiment was repeated twice. 
Table 1. Formulation and Composition of Experiment Diets (\% Dry Matter)

\begin{tabular}{|c|c|c|}
\hline Formulation & & \\
\hline Casein & 32 & 32 \\
\hline Gelatin & 8 & 8 \\
\hline Corn starch & 25 & 25 \\
\hline Fish oil & 3 & 5 \\
\hline Corn oil & 3 & 5 \\
\hline Cellulose & 18.50 & 14.50 \\
\hline Vitamin $\operatorname{mix}^{1}$ & 1 & 1 \\
\hline Mineral mix ${ }^{1}$ & 8 & 8 \\
\hline Ascorbic phosphate ester & 1 & 1 \\
\hline Choline chloride & 0.5 & 0.5 \\
\hline \multicolumn{3}{|l|}{ Composition } \\
\hline Moisture & 9.5 & 9.7 \\
\hline Crude protein & 35.85 & 35.24 \\
\hline Crude lipid & 5.6 & 9.7 \\
\hline Ash & 5.64 & 5.55 \\
\hline Crude energy $(\mathrm{kcal} / \mathrm{g})^{2}$ & 3 & 3.3 \\
\hline
\end{tabular}

${ }^{1 .}$ Vitamin mix and mineral mix was prepared as previous described by Du et al. [31].

2. The crude energy was calculated using physiological fuel value of $4.0,4.0$ and $9.0 \mathrm{kcal} \cdot \mathrm{g}^{-1}$ for protein, carbohydrate and lipid respectively.

Maximum daily consumption was determined after the intestinal evacuation experiment. Two control tanks without fish were used to measure the dissolving rate of the diet. The diets were oven-dried at $105^{\circ} \mathrm{C}$ for constant weight (Wa) and then put in eight tanks at 9:00AM, 12:00AM, 3:00PM and 6:00PM to let fish eat to satiety. The remaining diet in each tank was collected 90min after feeding and then oven-dried to constant weight (We for experimental tanks and $\mathrm{Wc}$ for the controls). The dissolving rate (DR) of diet was calculated as (Wa-Wc)/Wa. The diet consumption of fish during each feeding period in a single tank was calculated as $\mathrm{Wa}-\mathrm{We} /(1-$ DR). The maximum daily consumption of diet (Wm) in a single tank was calculated by summing the consumption of four time-points in a single tank. The maximum daily consumption of grass carp towards the two diets was calculated as $100 \times \mathrm{Wm} /$ fish weight in a single tank. The experiment was repeated in a time course as 1, 4, 7, 10, 13, 16, 19, 22 day with the same fish. Except experimental day, fish were foodrestricted. When all experimental repeats were completed, fish were weighed again.

\section{Statistical Analysis}

The data were subjected to one-way ANOVA to test the maximum daily consumption ratio in eight experimental repeats. When significant $(\mathrm{P}<0.05)$ difference was found, a Duncan's multiple range test was used to rank the repeats. All figures were made by Excel 2000 (Office 2000, Microsoft).

\section{RESULTS AND DISCUSSION}

The variation of intestinal content of grass carp after feeding is shown in Fig. (1). The intestinal content tended to decrease gradually until the $12^{\text {th }} \mathrm{h}$ and no significant difference was found between two diets with different energy level. However, in most of other fish species studied, gastrointestinal evacuation time normally exceed $24 \mathrm{~h}$ $[7,8,10,11,13,21,22]$. The intestinal evacuation time of grass carp $(12 \mathrm{~h})$ is much shorter than other fish. But it should be noticed that most fish studied are carnivorous or omnivorous, and also have well-developed stomach. In natural environment, the prey of these carnivorous or omnivorous fish consists of small fishes, shrimps and other aquatic animals [23]. However, grass carp is herbivorous and stomachless. Compared to the prey of other carnivorous or omnivorous fish, the natural food of grass carp is low-energy and lowprotein content, so it should be very necessary to improve the efficiency of digestion and absorption to shorten the passing time of food in intestine, for obtaining enough energy and protein. This hypothesis is supported by several evidences: 1) Grass carp have much longer intestine, 2.292.54 times to its body length, than carnivorous fish [24]. The long intestine could enlarge the surface area of digestion and absorption and it also could lead to shorten the evacuation time. 2) Li et al. [25] found in a single daytime, the time used of grass carp for eating is about $20 \mathrm{~h}$ and it only stops eating in midnight for $4 \mathrm{~h}$ in natural environment. It proves that the ability of digestion in grass carp was strong. 3) Li et al. [25] also found when grass carp was fed phytoplankton and vege- 


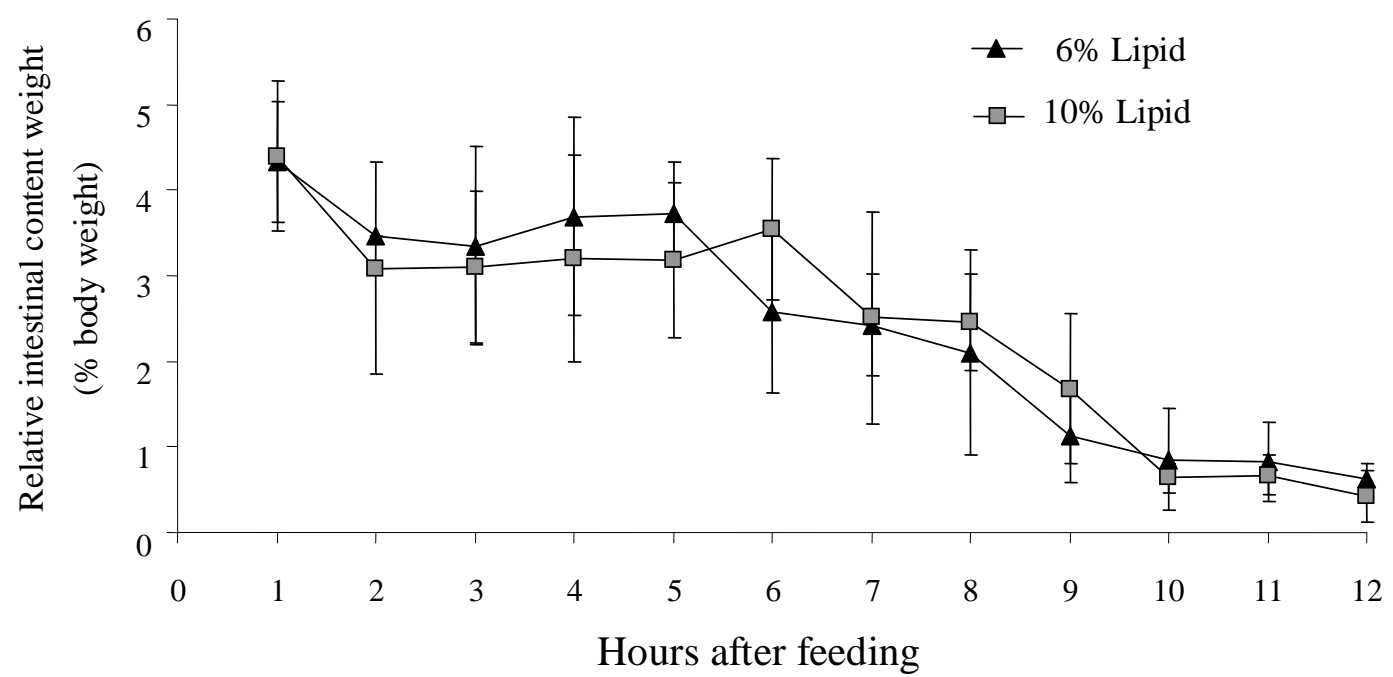

Fig. (1). Intestinal evacuation rate of grass carp towards two purified formulated diets with different lipids content.

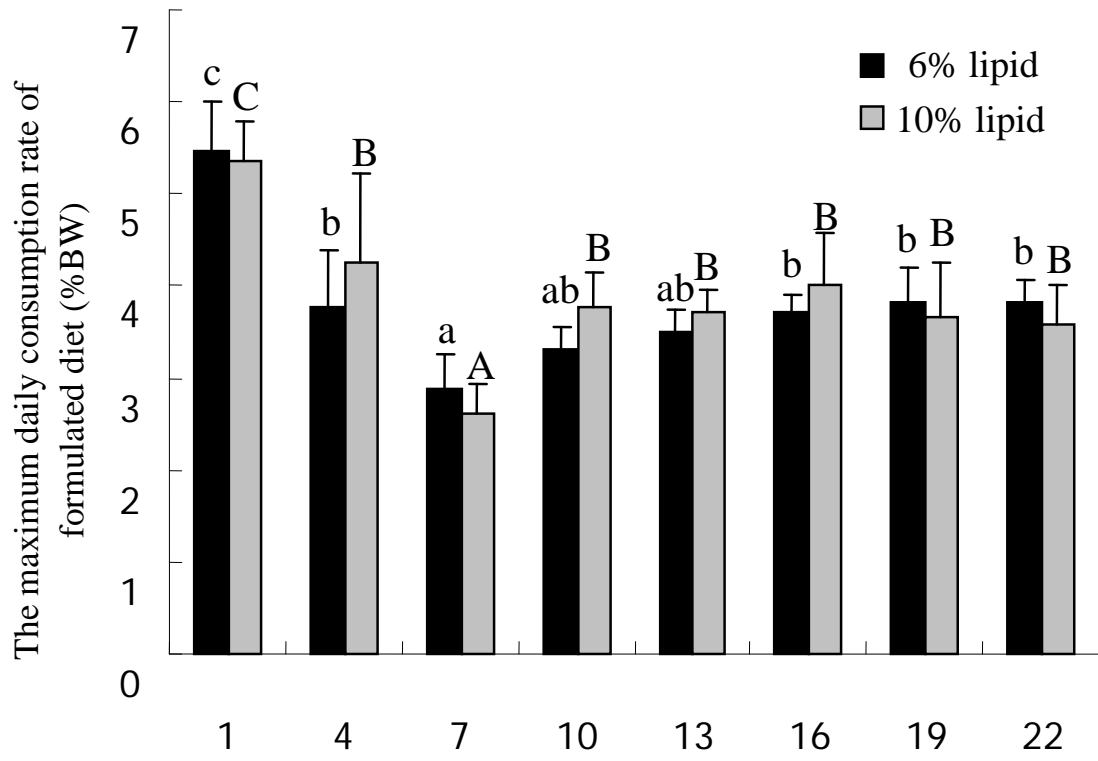

Experimental repeats by time course (day)

Fig. (2). The maximum daily consumption of two purified formulated diet with different lipids content in grass carp. Within the same diet, the values with different superscripts are significantly different $(P<0.05)$.

table to satiety, it only needed $4 \mathrm{~h}$ to evacuate all the content in intestine. Jobling [23] believed the evacuation of highenergy density artificial diet was slower than prey in natural environment, which was also confirmed by the present study which demonstrated that the intestinal evacuation time of formulated diet (12h) is 3 times longer than natural food of grass carp.

Linear, square root and exponential regression were normally used for description of gastrointestinal evacuation progress [26]. In the present study, linear, square root and exponential regression models were built and compared respectively, and the linear model was better than the other regressions. For 6 and 10\% diet, the linear regression was $\mathrm{Y}=4.6988-0.3498 \mathrm{X} \quad\left(\mathrm{R}^{2}=0.9206\right)$ and $\mathrm{Y}=4.5321-0.3268 \mathrm{X}$ $\left(\mathrm{R}^{2}=0.8471\right)$ respectively. Here $\mathrm{X}$ is the time $(\mathrm{h})$ and $\mathrm{Y}$ is the intestinal content. This result is similar to many mammals [27], but contrary to carnivorous/omnivorous fish $[6,11,12]$. It may be explained by the large surface-to-volume ratio in intestine of grass carp and it makes the progress of digestion and absorption turn evener and smoother than other fish which have stomach and shorter intestine.

The maximum daily diet consumptions of eight experimental repeats are shown in Fig. (2). The trend of two diets was similar. In the first three experimental repeats, the maximum diet consumption decreased quickly $(\mathrm{P}<0.05)$. From the $10^{\text {th }}$ day, the maximum daily diet consumption increased again and stayed constant $(\mathrm{P}>0.05)$. The average of the data from $10^{\text {th }}$ day to $22^{\text {th }}$ day was $3.64 \pm 0.23 \% \mathrm{BW}$ $\left(456.46 \pm 28.84 \mathrm{~J} / \mathrm{g} . \mathrm{d}^{-1}\right)$ for $6 \%$ dietary lipid level and $3.75 \pm$ $0.16 \%$ BW $\left(481.73 \pm 19.44 \mathrm{~J} / \mathrm{g} \cdot \mathrm{d}^{-1}\right)$ for $10 \%$ dietary lipid 
level, and there was no significant difference. It could be explained that after three repeats, fish had acclimated the feeding quantity and frequency. Li et al. [25] found when grass carp (4.9-650g) were fed phytoplankton and vegetable, the maximum daily consumption ratio was $41.5-49.8 \% \mathrm{BW}$ in July and August at south China, which is much higher than $3.6 \%$ and $3.8 \% \mathrm{BW}$ in present study. But considering the high content of moisture and fiber in water plant, high food consumption is necessary for grass carp to intake enough energy for survive in nature.

Many mathematical models were set up to estimate the relationship between daily food consumption and fish size or water temperature $[2,16,28]$. In an appropriate range of temperature, daily food consumption increased with the increase of fish size and temperature, but daily food consumption decreased with the increase of fish size. The maximum daily food consumption of some fish in different conditions was monitored, such as $2.99-3.46 \% \mathrm{BW}$ in juvenile Florida pompano [19], 436.2 J/g.d ${ }^{-1}$ in southern catfish [29], and 810.84 $\mathrm{J} / \mathrm{g} \cdot \mathrm{d}^{-1}$ in Crescent Sweetlips (Plectorhynchus cinctus) [30]. In the present study, the maximum daily diet consumption, $3.64 \pm 0.23 \% \mathrm{BW}\left(456.46 \pm 28.84 \mathrm{~J} / \mathrm{g} . \mathrm{d}^{-1}\right)$, gained at relative high water temperature, could be regarded as the maximum daily consumption of grass carp towards these formulated diets in this experimental condition. However, in an 8 weeks trial performed in winter [31], the proper feeding rate of a similar formulated diet in grass carp was determined as $2 \%$ BW and excess feed intake would decrease the feed efficiency and digestibility efficiency. So the maximum daily consumption which is got from a short term trial probably needs to regulate to fit longer aquaculture term. In other longer feeding trials [32,33], the differences in growth, body composition and biochemical alteration induced by different dietary energy level have been observed, and these studies also indicated that compared to other carnivorous and omnivorous fish, grass carp is a low-energy requirement fish species. However, in this short term trial, no significant differences were found between two diets with different energy content.

\section{REFERENCES}

[1] Tyler AV. Rate of gastric emptying in young cod. J Fish Res Board Can 1970; 27: 1177-89.

[2] Jobling M. Mathematical models of gastric emptying and the estimation of daily rates of food consumption for fish. J Fish Biol 1981; 19: 245-57.

[3] Tallot C. Laboratory methods in fish feeding and nutritional studies. In: Tyler P, Calow P, (Eds). Fish Energetics: New Perspectives. Croom Helm, London, 1985; pp.125-54.

[4] Flowerdew MW, Grove DJ. Some observations of the effects of body weight, temperature, meal size and quality on gastric emptying time in the turbot Scophthalmus maximus (L.) using radiography. J Fish Biol 1979; 14: 229-38.

[5] Garber KJ. Effect of fish size, meal size and dietary mositure on gastric evacuation of pelleted diets by yellow perch, Perca Flavescens. Aquaculture 1983; 34: 41-9.

[6] Jobling M. Influences of food particle size and dietary energy content on patterns of gastric evacuation in fish: test of a physiological model of gastric emptying. J Fish Biol 1987; 30: 299-314.

[7] Storebakken T, Kvien IS, Shearer KD. Estimation of gastrointestinal evacuation rate in Atlantic salmon (Salmo salar) using inert markers and collection of faeces by sieving: evacuation of diets with fish meal, soybean meal of bacterial meal. Aquaculture 1999; 172: 291-9.
[8] Sveier H, Wathne E, Lied E. Growth, feed and nutrient utilization and gastrointestinal evacuation time in Atlantic salmon (Salmo salar L.): the effect of dietary fish meal particle size and protein concentration. Aquaculture 1999; 180: 265-82.

[9] Elliott JM. Rates of gatric evacuation in brown trout, Salmo trutta L. Freshw Biol 1972; 2: 1-18.

[10] Jobling M. Gastric evacuation in plaice, Pleuronectes platessa L.: effects of dietary energy level and food composition. J Fish Biol 1980; 17: 187-96.

[11] Basimi RA, Grove DJ. Gastric emptying rate in Pleuronectes platessa L. J Fish Biol 1985; 26: 545-52.

[12] Brodeur RD. Gastric evacuation rates for two foods in the black rockfish, Seabastes melanops Girard. J Fish Biol 1984; 24: 287-98.

[13] Lee SM, Hwang UG, Cho SH. Effects of feeding frequency and dietary moisture content on growth, body composition and gastric evacuation of juvenile Korean rockfish (Sebastes schlegeli). Aquaculture 2000; 187: 399-409.

[14] Medved RJ. Gastric evacuation in the sandbar shark, Carcharhinus plumbeus. J Fish Biol 1985; 26: 239-53.

[15] Wootton RJ, Allen JRM, Cole SJ. Effect of body weight and temperature on the maximum daily food consumption of Gsaterosteus aculeatus L. and Phoxinus phoxinus (L.): selecting an appropriate model. J Fish Biol 1980; 17: 695-705.

[16] Cui Y, Wootton RJ. Bioenergetics of growth of a cyprinid, Phoxinus phoxinus: the effect of ration, temperature and body size on food consumption, faecal production and nitrogenous excretion. J Fish Biol 1988; 33: 431-43.

[17] Hop H, Tonn WM, Welch HE. Bioenergetics of Arctic cod (Boreogadus saida) at low temperatures. Can J Fish Aqua Sci 1997; 54: 1772-84.

[18] Chen Z, Ding G, Luo F. A study on consumption of thirty-two herbages by two groups of green carps. J Yunnan Agric Univ 1998; 13: 411-4.

[19] Heliman MJ, Spieler RE. The daily feeding rhythm to demand feeders and the effects of timed meal-feeding on the growth of juvenile Florida pompano, Trachinotus carolinus. Aquaculture 1999; 180: 53-64.

[20] Du ZY, Liu YJ, Tian LX. Effect of dietary lipid level on growth, feed utilization and body composition by juvenile grass carp (Ctenopharyngodon idella). Aquacult Nutr 2005; 11: 139-46.

[21] Thia-Eng C, Seng-Keh T. Effects of feeding frequency on the growth of young estuary grouper, Epinephelus tauvina (Forskal), cultured in floating net-cages. Aquacultue 1978; 14: 31-43.

[22] Fauconneau B, Choubert G, Blanc D. Influence of environmental temperature on flow rate of foodstuffs through the gastrointestinal tract of rainbow trout. Aquaculture 1983; 34: 7-39.

[23] Jobling M. Gastrointestinal overload-a problem with formulated feed? Aquaculture 1986; 51: 257-63.

[24] Lin HR. The physiology of fishes. Guangdong Higher Education Press. Guangzhou, 1999; pp. 35-54.

[25] Li S, Yang H, Lu W. Preliminary research on diurnal feeding rhythm and the daily ration for silver carp, bighead carp and grass carp. J Fish China 1980; 4: 275-83.

[26] He E, Wurtsbaugh WA. An empirical model of gastric evacuation rates for fish and an analysis of digestion in piscivorous brown trout. Trans Am Fish Soc 1993; 122: 717-30.

[27] Kalogeris TJ, Reidelberger RD, Mendel VE. Effect of nutrient density and composition of liquid meals on gastric emptying in feeding rats. Am J Physiol 1983; 244: R865-R71.

[28] Elliott JM. Energestics of freshwater teleosts. Symp Zool Soc Lond 1979; 44: 29-61.

[29] Xie XJ, Sun RY. Maximum ration level in the southern catfish (Silurus meridionalis Chen). Acta Ecol Sin 1992; 12: 225-31.

[30] Wang M, Qiu S. Effect of temperature and body weight on maximum food consumption of juvenile Plectorhynchus cinctus. J Ocea Taiwan Strait 2000; 19: 484-8.

[31] Du ZY, Liu YJ, Tian LX, He JG, Cao JM, Liang GY. The influence of feeding rate on growth, feed efficiency and body composition of juvenile grass carp (Ctenopharyngodon idella). Aquacult Int 2006; 14: 247-57. 
[32] Du ZY, Clouet P, Zheng WH, Degrace P, Tian LX, Liu YJ. Biochemical hepatic alterations and body lipid composition in the herbivorous grass carp (Ctenopharyngodon idella) fed high-fat diets. Br J Nutr 2006; 95: 905-15.
[33] Du ZY, Clouet P, Huang LM, et al. Utilization of different dietary lipid sources at high level in herbivorous grass carp (Ctenopharyn godon idella): mechanism related to hepatic fatty acid oxidation. Aquacult Nutr 2008; 14: 77-92.

Received: November 17, 2008

Revised: November 27, 2008

Accepted: November 28, 2008

(C) Du et al.; Licensee Bentham Open.

This is an open access article licensed under the terms of the Creative Commons Attribution Non-Commercial License (http://creativecommons.org/licenses/by-nc/3.0/) which permits unrestricted, non-commercial use, distribution and reproduction in any medium, provided the work is properly cited. 